\title{
MicroRNA-125b expression in gastric adenocarcinoma and its effect on the proliferation of gastric cancer cells
}

\author{
ZHAO-XU YANG $^{1^{*}}$, CHENG-YI LU $^{2 *}$, YAN-LING YANG ${ }^{1}$, KE-FENG DOU $^{1}$ and KAI-SHAN TAO ${ }^{1}$ \\ ${ }^{1}$ Department of Hepatobiliary Surgery, Xijing Hospital of the Fourth Military Medical University, Xi'an 710032; \\ ${ }^{2}$ Department of Information, Tangdu Hospital of the Fourth Military Medical University, Xi'an 710038, P.R. China
}

Received August 29, 2012; Accepted October 17, 2012

DOI: $10.3892 / \mathrm{mmr} .2012 .1156$

\begin{abstract}
MicroRNAs exert regulatory effects on a number of genes, thereby contributing to both physiological and pathological processes. The functions of microRNAs in tumorigenesis are becoming increasingly clear. In the present study, we investigated the role of microRNA-125b (miR-125b), previously implicated in prostate and breast cancer, in gastric cancer, particularly regarding proliferation and apoptosis of gastric cancer cells. The expression of miR-125b was measured in 50 samples of gastric cancer tissues and corresponding paracancerous tissues by real-time PCR. The levels of miR-125b expression in the gastric cancer tissues were significantly higher compared to the adjacent normal tissues $(\mathrm{P}<0.05)$. To begin to understand how the increased expression of miR-125b may promote gastric cancer, the miR-125b mimic was transfected into the gastric cancer cell line, HGC-27, for the determination of proliferation (CCK8) and apoptosis (Annexin V) by flow cytometry. The results demonstrated that the proliferation significantly increased and apoptosis significantly decreased in the HGC-27 cells following transfection with the miR-125b mimic, compared to the untreated and scramble-treated controls $(\mathrm{P}<0.05)$. Thus, miR-125b may act as an oncogene in gastric cancer by dysregulating gastric cell proliferation and apoptosis.
\end{abstract}

\section{Introduction}

MicroRNAs (miRNAs) are a very important regulatory RNA molecules that influence gene function by inhibiting translation or inducing the degradation of target mRNA (1). Importantly, expression imbalances caused by miRNA regulation can contribute to the pathogenesis of various tumors (2). For example, miR-21 has been implicated in breast, colon, prostate

Correspondence to: Dr Tao Kai-Shan, Department of Hepatobiliary Surgery, Xijing Hospital, the Fourth Military Medical University, 15 Changlexi Road, Xi'an 710032, P.R. China

E-mail: yangzx710032@126.com

*Contributed equally

Key words: gastric cancer, microRNA-125b, HCG-27 cells, proliferation, apoptosis and thyroid cancers, among others (2). The potent effect of miRNAs on disease processes indicates a need for studying their expression and function, with the aim of establishing a solid foundation for the clinical treatment of tumors (3-5).

Another miRNA, miR-125b, has been shown to exhibit abnormal expression in a variety of tumor tissues; however, its effects are not consistent across tissue types (6-8). In prostate cancer, the high expression of miR-125b can promote tumor proliferation (9), but, in breast cancer, miR-125b can significantly inhibit tumor proliferation (10). A certain study found that this miRNA exhibited altered expression in gastric cancer according to disease progression (11). However, no other reports on miR-125b expression and its effect on gastric cancer have been identified.

Gastric cancer occurs with high incidence in Asian populations and thus has been an important focus of cancer research (12). In this study, real-time PCR was used to detect miR-125b expression in 50 cases of gastric cancer tissues and corresponding adjacent normal tissues. To determine the effect of miR-125b on the proliferation and apoptosis of gastric cancer cells, the miR-125b mimic was transfected into the gastric cancer cell line, HGC-27. Our results reveal the potential functions of miR-125b in gastric cancer and may pave the way for its application in clinical diagnosis and treatment.

\section{Materials and methods}

Specimens. Specimens of both gastric carcinoma tissues and corresponding adjacent normal tissues ( $>5 \mathrm{~cm}$ away from cancer tissues) were collected from 50 patients who received surgical resection of gastric cancer from January 2010 to December 2011 in Xijing Hospital, the Fourth Military Medical University, Xi'an, China. Gastric cancer diagnoses were confirmed by post-operative pathological biopsy. No patients had received pre-operative radiotherapy, chemotherapy or endocrine therapy. The age range of the patients was 32-70 years and the mean age was 53.9 \pm 9.6 years. During surgery, the cancer and adjacent normal tissues were cut, $100 \mathrm{mg}$ of which were washed with $1 \mathrm{X}$ PBS, placed in cryovials and kept in a refrigerator at $-80^{\circ} \mathrm{C}$.

Cell culture and transfection. The HGC-27 human gastric cancer cells were provided by the Cell Bank of the Shanghai Institute of Cell Biology (Chinese Academy of Sciences, 
Shanghai, China) and placed in DMEM medium (Gibco-BRL, Carlsbad, CA, USA) containing 10\% FBS (PAA Laboratories, Pasching, Austria), $1 \times 10^{5} \mathrm{IU} / 1$ penicillin and $1 \times 10^{5} \mathrm{IU} / 1$ streptomycin and conventionally cultured in an incubator at $37^{\circ} \mathrm{C}$, $5 \% \mathrm{CO}_{2}$. One day prior to transfection, the cell culture medium was transferred at a density of $1 \times 10^{4}$ cells $/ \mathrm{ml}$ to prepare for transfection during the logarithmic growth phase. Cells were washed once with serum-free medium, then resuspended in complete medium without antibiotics at a cell concentration of $4 \times 10^{5}$ in a volume of $1,500 \mu \mathrm{l}$. Suspensions were transferred onto a 6-well plate and placed in DMEM overnight without serum and antibiotics. Transfections were performed with DharmaconFECT1 (Dharmacon, Inc., Lafayette, CO, USA), using 100 pmol mimic-miR-125b (Dharmacon Inc.) per well in the transfection group and 100 pmol negative control (Dharmacon Inc.) per well in the control group. After $6 \mathrm{~h}$ of culture at $37^{\circ} \mathrm{C}, 5 \% \mathrm{CO}_{2}, 500 \mu \mathrm{l}$ of $10 \%$ FBS-supplemented medium were added and the cells were continuously cultured for $72 \mathrm{~h}$.

Detecting cell proliferation with CCK-8. Suspensions containing $5 \times 10^{4}$ cells $/ \mathrm{ml}$ were prepared and $100 \mu \mathrm{l}$ of suspension were added to a 96-well plate. Cells were continuously cultured at $37^{\circ} \mathrm{C}$. At 24,48 and $72 \mathrm{~h}$ after culture, $10 \mu 1$ CCK- 8 solution (Dojindo, Kunamoto, Japan) were added to each well before an additional incubation at $37^{\circ} \mathrm{C}$ for $4 \mathrm{~h}$. The optical density of the suspensions was then determined by absorbance at $450 \mathrm{~nm}$.

Detecting cell apoptosis with FITC-Annexin V. The cells were collected into $10-\mathrm{ml}$ centrifuge tubes and washed with incubation buffer. Following centrifugation at $800 \mathrm{rpm}$ for $5 \mathrm{~min}$, the cells were resuspended in $100 \mu 1$ FITC-Annexin V-PI (BD Biosciences, Franklin Lakes, NJ, USA) labeling solution and incubated at room temperature in the dark for $15 \mathrm{~min}$. Following another centrifugation at $800 \mathrm{rpm}$ for $5 \mathrm{~min}$, the cells were washed with incubation buffer. Fluorescent dye solution was added and the cells were incubated at $4^{\circ} \mathrm{C}$ for $20 \mathrm{~min}$ in the dark with occasional mixing. The excitation wavelength for flow cytometry was $488 \mathrm{~nm}$; FITC was detected at $515 \mathrm{~nm}$ and PI was detected at $>560 \mathrm{~nm}$. Data were plotted in bivariate flow cytometry scatter plots: the lower left quadrant (FITC-/PI-) shows living cells; the upper right quadrant $\left(\mathrm{FITC}^{+} / \mathrm{PI}^{+}\right)$shows non-living cells, namely, necrotic cells; the lower right quadrant $\left(\mathrm{FITC}^{+} / \mathrm{PI}\right)$ indicates apoptotic cells.

Quantitative real-time PCR. TRIzol reagent (Invitrogen Life Technologies, Carlsbad, CA, USA) was used according to the manufacturer's instructions to extract the total cellular RNA from the tissue specimens; RNA purity and concentration were determined by UV spectrophotometry. MiRNA 1st-strand cDNA was synthesized by stem-loop primer reverse transcription reaction (Promega Corp., Madison, WI, USA). The following primer sequences were used: Hsa-miR-125b RT primer, 5'-GTCGTATCCAGTGCAGGGTCCGAGGTATTC GCACTGGATACGACTCACAAG-3'; Hsa-miR-125b sense primer, 5'-GGATTCCCTGAGACCCTAAC-3'; Hsa-miR-125b antisense primer, 5'-GTGCAGGGTCCGAGGT-3'; U6 RT primer, 5'-AAAATATGGAACGCTTCACGAATTTG-3'; U6 sense primer, 5'-CTCGCTTCGGCAGCACATATACT- 3'; U6 antisense primer, 5'-ACGCTTCACGAATTTGCGTGTC-3'.

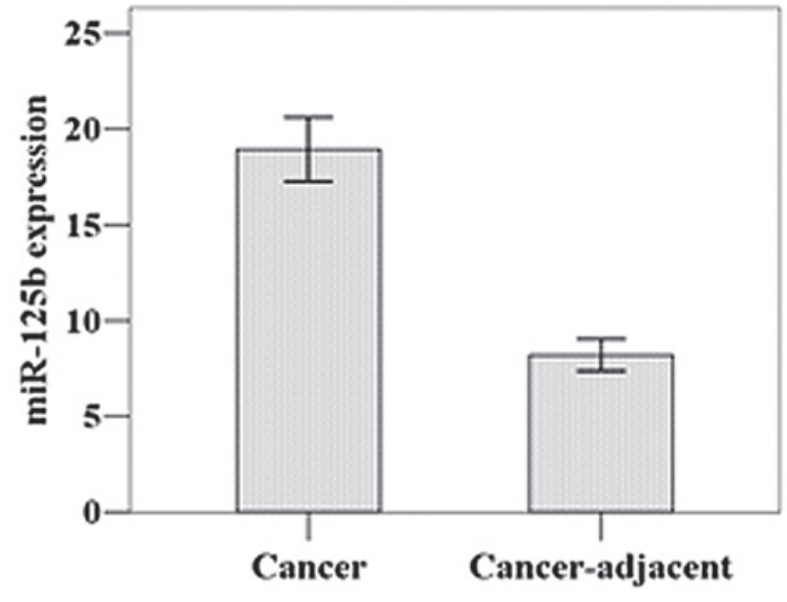

Figure 1. Expression of miR-125b in gastric cancer and adjacent normal tissues by real-time PCR.

The real-time quantitative PCR kit (Takara Bio., Inc., Shiga, Japan) was used to facilitate the reactions. Reactions were performed under the following thermal cycling conditions: $94^{\circ} \mathrm{C}$ for $20 \mathrm{sec}$; and 40 cycles of $94^{\circ} \mathrm{C}$ for $30 \mathrm{sec}, 60^{\circ} \mathrm{C}$ for $45 \mathrm{sec}$. Samples were amplified in triplicate and reactions were performed on a Bio-Rad IQ5 PCR instrument (Bio-Rad, Hercules, CA, USA) which was also used to analyze the results.

Statistical analysis. SPSS17.0 statistical software was applied to statistical analysis. Measurement data are expressed as the means \pm standard deviation (SD). A two-independent-sample $\mathrm{t}$-test was used to compare the miR-125b expression between the groups. The above analyses were performed with two-sided tests, with a test level $(\alpha)$ of 0.05 and $\mathrm{P}<0.05$ was considered to indicate a statistically significant difference.

\section{Results}

MiR-125b expression in gastric cancer and adjacent noncancerous tissues. As shown by real-time PCR, the relative mean miR-125b expression level was $18.94 \pm 5.96$ in the gastric cancer tissues and $8.20 \pm 2.91$ in the adjacent normal tissues (Fig. 1). This difference was statistically significant $(t=11.452$, $\mathrm{P}=0.001$ ).

Effect of miR-125b overexpression on HGC-27 cell proliferation . The miR-125b expression level was detected at $1192.00 \pm 109.77$ in the HGC-27 cells transfected with miR-125b mimic, a significant increase of approximately 1000 -fold compared to the cells treated with the scrambled miRNA $(1.29 \pm 0.18)(\mathrm{t}=18.788$, $\mathrm{P}=0.001$ ); thus, the transfection was successful (Fig. 2). The subsequent CCK8 proliferation assay demonstrated that the proliferation was significantly increased in the miR-125b-overexpressing cells compared to the untreated and scramble-treated cells $(\mathrm{F}=23.095, \mathrm{P}=0.002)$ (Fig. 3).

Effect of miR-125b overexpression on HGC-27 cell apoptosis. To determine whether the apoptosis of HGC-27 cells is also dysregulated when miR-125b is overexpressed, the cells were 


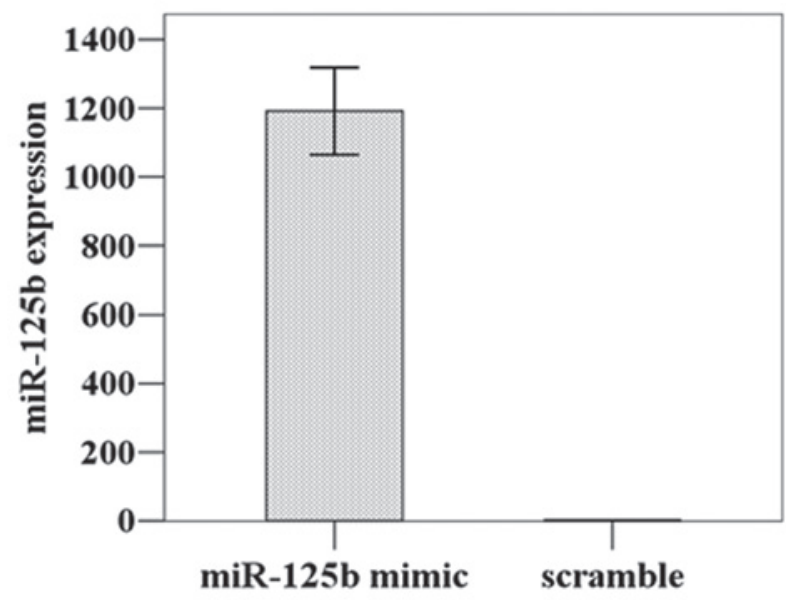

Figure 2. Real-time PCR results of the miR-125b expression level of in HGC-27 cells transfected with the miR-125b mimic or scrambled RNA.

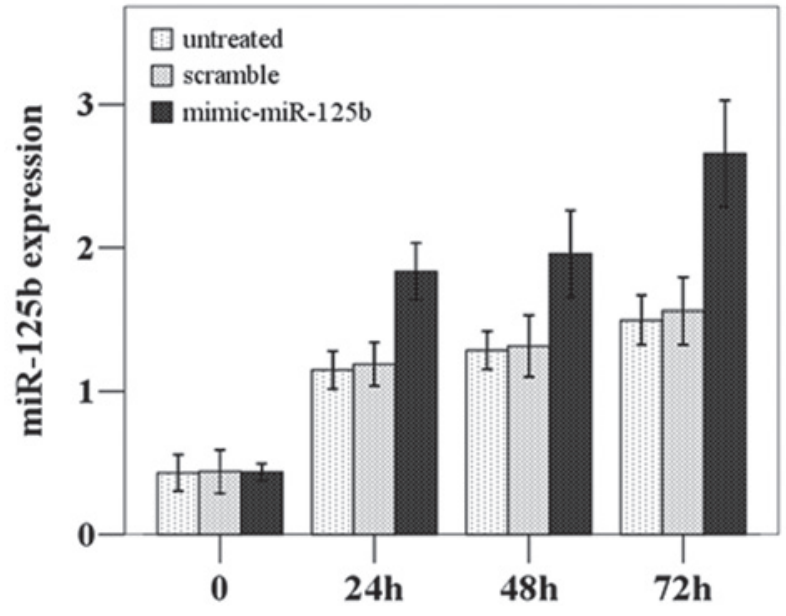

Figure 3. Proliferation of HGC-27 cells with overexpression of miR-125b, as detected by flow cytometry with CCK8 proliferation marker.
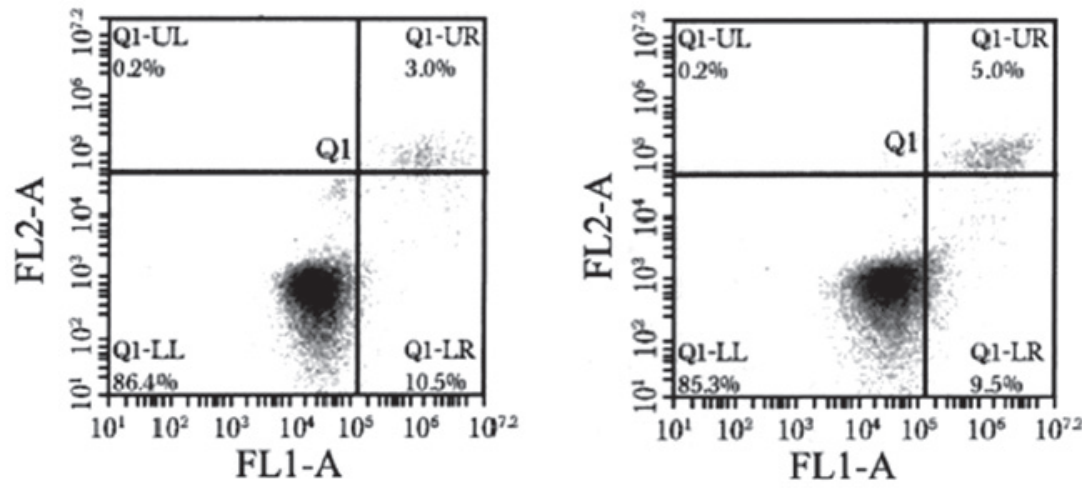

Figure 4. Apoptosis of HGC-27 cells with overexpression of miR-125b, as detected by flow cytometry with Annexin V labeling.

Table I. Mean percentage of early and late apoptotic HGC-27 cells from three independent experiments.

\begin{tabular}{lcc}
\hline Treatment & $\begin{array}{c}\text { Early } \\
\text { apoptotic cells }\end{array}$ & $\begin{array}{c}\text { Late } \\
\text { apoptotic cells }\end{array}$ \\
\hline Mimic-miR-125b & $6.47 \pm 0.39$ & $3.94 \pm 0.20$ \\
Scramble & $9.04 \pm 0.70^{\mathrm{a}}$ & $3.09 \pm 0.09^{\mathrm{a}}$ \\
Untreated & $10.64 \pm 1.21^{\mathrm{a}, \mathrm{b}}$ & $4.34 \pm 0.07^{\mathrm{a}, \mathrm{b}}$ \\
F-value & 18.909 & 72.337 \\
P-value & 0.003 & 0.001 \\
\hline
\end{tabular}

${ }^{\mathrm{a}}$ vs. mimic-miR-125b, $\mathrm{P}<0.05 ;{ }^{\mathrm{b}} \mathrm{vs}$. scramble, $\mathrm{P}<0.05$.

analyzed by flow cytometry for Annexin V. The proportion of Annexin V-positive cells was decreased when miR-125b was overexpressed, which can be observed mainly as the percentage of cells in early apoptosis (lower right quadrant, Fig. 4). Furthermore, in HGC-27 cells expressing the miR-125b mimic, the early and late apoptotic rates were different compared to the scramble-treated and untreated cells $(\mathrm{P}<0.05$, Table I).

\section{Discussion}

The potent ability of miRNAs to regulate a variety of physiological and pathological processes is well-accepted as a key component of gene expression regulatory networks in eukaryotes. Indeed, these molecules exert effects on cell proliferation and apoptosis, organismal growth and development, hematopoiesis and organ formation (13). Recent studies on tumor-associated miRNAs have uncovered roles for a number of miRNA molecules in tumorigenesis, as well as in cancer diagnosis and prognosis $(2,14)$.

Our current study on the expression of miR-125b (previously implicated in other tumors types), in gastric cancer confirms the results from a previous study, demonstrating its dysregulation in this type of cancer (11). Furthermore, the overexpression of this miRNA in gastric cancer cells in vitro revealed the affects on cellular proliferation and apoptosis; proliferation was increased and apoptosis decreased when miR-125b was overexpressed. The dysregulation of these cellular processes by miR-125b may promote tumor initiation and progression. These results indicate that miR-125b plays an important role in the pathogenesis of gastric cancer. Further studies are required to determine whether miR-125b 
represents a potential oncogenic target for the diagnosis and treatment of gastric cancer.

\section{Acknowledgements}

This study was supported by the National Science Foundation of China (grant no. 81000164).

\section{References}

1. Iorio MV and Croce CM: MicroRNAs in cancer: small molecules with a huge impact. J Clin Oncol 27: 5848-5856, 2009.

2. Nikitina EG, Urazova LN and Stegny VN: MicroRNAs and human cancer. Exp Oncol 34: 2-8, 2012.

3. Esquela-Kerscher A and Slack FJ: Oncomirs-microRNAs with a role in cancer. Nat Rev Cancer 6: 259-269, 2006.

4. Hobert O: Gene regulation by transcription factors and microRNAs. Science 319: 1785-1786, 2008.

5. Kota J, Chivukula RR, O'Donnell KA, et al: Therapeutic microRNA delivery suppresses tumorigenesis in a murine liver cancer model. Cell 137: 1005-1017, 2009.

6. Xu N, Brodin P, Wei T, et al: MiR-125b, a microRNA downregulated in psoriasis, modulates keratinocyte proliferation by targeting FGFR2. J Invest Dermatol 131: 1521-1529, 2011.
7. Shi XB, Xue L, Ma AH, Tepper CG, Kung HJ and White RW: miR-125b promotes growth of prostate cancer xenograft tumor through targeting pro-apoptotic genes. Prostate 71: 538-549, 2011.

8. Glud M, Rossing M, Hother C, et al: Downregulation of miR-125b in metastatic cutaneous malignant melanoma. Melanoma Res 20: 479-484, 2010.

9. Shi XB, Xue L, Yang J, et al: An androgen-regulated miRNA suppresses Bak1 expression and induces androgen-independent growth of prostate cancer cells. Proc Natl Acad Sci USA 104: 19983-19988, 2007.

10. Scott GK, Goga A, Bhaumik D, Berger CE, Sullivan CS and Benz CC: Coordinate suppression of ERBB2 and ERBB3 by enforced expression of micro-RNA miR-125a or miR-125b. J Biol Chem 282: 1479-1486, 2007.

11. Ueda T, Volinia S, Okumura H, et al: Relation between microRNA expression and progression and prognosis of gastric cancer: a microRNA expression analysis. Lancet Oncol 11: 136-146, 2010.

12. Lochhead P and El-Omar EM: Helicobacter pylori infection and gastric cancer. Best Pract Res Clin Gastroenterol 21: 281-297, 2007.

13. Bartel DP: MicroRNAs: genomics biogenesis, mechanism and function. Cell 116: 281-297, 2004.

14. Croce C: Introduction to the role of microRNAs in cancer diagnosis, prognosis and treatment. Cancer J 18: 213-214, 2012. 